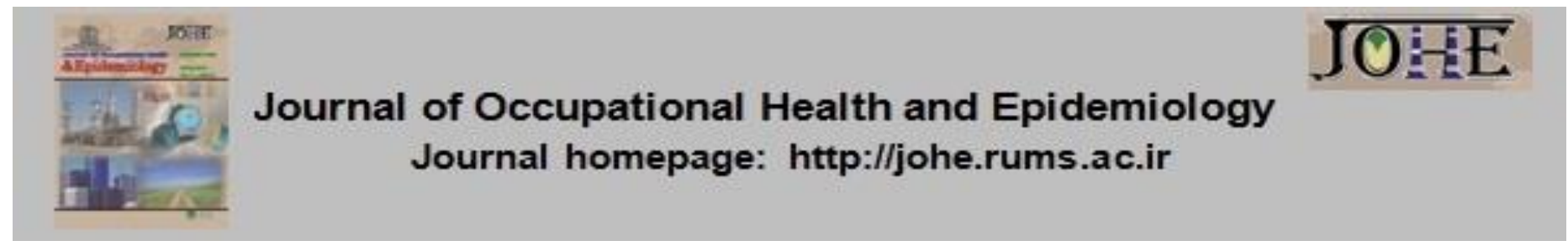

\title{
Changes of Genetic Loci among Gastric Cancer Patients, Southeastern Iran, 2017
}

\author{
Saeedeh Salari ${ }^{1}$, Mojgan Noroozi Karimabad², Masoud Torkzadeh Mahani ${ }^{3}$, Nahid Askari ${ }^{4}$, \\ Mohammad Reza Hajizadeh ${ }^{5}$, Mehdi Mahmoodi ${ }^{*}$
}

1. MSc in Clinical Biochemistry, Dept. of Clinical Biochemistry, Faculty of Medicine, Rafsanjan University of Medical Sciences, Rafsanjan, Iran.

2. Assistant Prof., Molecular Medicine Research Center, Research Institute of Basic Medical Sciences, Rafsanjan University of Medical Sciences, Rafsanjan, Iran.

3. Associate Prof., Dept. of Biotechnology, Institute of Science and High Technology and Environmental Sciences, Graduate University of Advanced Technology, Kerman, Iran.

4. Assistant Prof., Dept. of Biotechnology, Institute of Science and High Technology and Environmental Sciences, Graduate University of Advanced Technology, Kerman, Iran.

5. Associate Prof., Dept. of Clinical Biochemistry, Faculty of Medicine, Rafsanjan University of Medical Sciences, Rafsanjan, Iran; Molecular Medicine Research Center, Research Institute of Basic Medical Sciences, Rafsanjan University of Medical Sciences, Rafsanjan, Iran.

6. Prof., Dept. of Clinical Biochemistry, Afzalipoor Faculty of Medicine, Kerman University of Medical Sciences, Kerman, Iran; Molecular Medicine Research Center, Research Institute of Basic Medical Sciences, Rafsanjan University of Medical Sciences, Rafsanjan, Iran.

Citation: Salari S, Noroozi Karimabad M, Torkzadeh Mahani M, Askari N, Hajizadeh MR,
Mahmoodi M. Changes of Genetic Loci among Gastric Cancer Patients, Southeastern Iran,
2017. JOHE 2020; 9(4):194-205.

\section{Article Info}

\section{* Corresponding author:}

Mehdi Mahmoodi,

E-mail:

mahmoodies@yahoo.com

\section{Article history}

Received: Aug 2020

Accepted: Jan 2021

10.29252/johe.9.4.194

Print ISSN: 2251-8096 Online ISSN: 2252-0902

Peer review under
responsibility of Journal of
Occupational Health and
Epidemiology

\begin{abstract}
Background: Characterization of genes and precise assessment of the number of copies are crucial for understanding the basis of emergence, progression, and identification of predictive markers of tumor malignancy. This study aimed to investigate the role of the changes in some central genes in gastric cancer.

Materials and Methods: In this experimental study, 30 patients with gastric surgery were selected by random sampling from four hospitals in Kerman to investigate BAX, BCL-2, P53, and MICAL-2 genes in cancerous and healthy tissues. They were then studied using real-time RT-qPCR, PCR- SSCP, and sequencing.

Results: Demographic analysis demonstrated that $66.6 \%$ of patients with gastric cancer were men. The age range of men and women was $26-93$ and $33-83$ years, respectively. In terms of tumor pathology, there was $93.3 \%$ adenocarcinoma, $6.6 \%$ gastrointestinal stromal tumor (GIST), 16.6\% intestinal type, 10\% diffuse type, and 73.3\% unknown type. The two exons of the p53 gene showed a 2.04 and 3.81 fold increase in expression relative to normal adjacent tissue. Results showed the upregulation of $\mathrm{Bcl}-2(1.54 \%)$ and MICAL2 (2.23\%), while the expression of Bax was downregulated (0.87\%). Bcl-2/Bax ratio was not solely correlated with the progression and clinical outcome of gastric cancer.

Conclusion: The data suggest that the changes in BAX, BCL2, P53, and MICAL-2 genes play a key role in gastric cancer.
\end{abstract}

Keywords: BAX, BCL2, P53, MICAL-2, Sequencing, Gene.

\section{Introduction}

Cancer is among the leading reasons for mortality around the globe. It is a long-term process that occurs as a result of abnormal changes in various genes and imbalances in cell cycle regulator mechanisms. Cancer has been demonstrated as 
the third most common mortality factor in Iran, so that $14 \%$ of deaths are related to cancer. Invasion and metastasis are critical determinants of cancer deaths. The genes and molecules participating in these processes must be considered as potential prognostic factors. The incidence of gastric cancer, as a major global health concern, is affected by geographic and ethnic differences all over the world [1]. In recent years, various reports have shown that gastric cancer is the fourth most prevalent cancer in Iran [2,3]; it is estimated to be the second most common malignancy worldwide. Global estimations have demonstrated that more than 930,000 new gastric cancer cases are diagnosed annually, 700,000 of which are dead [4]. Even though the incidence of gastric cancer is declining, the outcomes of patients with the disease remain disappointing since no sensitive biomarker is available for early prediction of recurrence and chemosensitivity [3, 5]. Infection with Helicobacter pylori represents a strong and established risk factor for gastric cancer; however, it is not sufficient to develop this cancer [6]. Gastric cancer displays transformations in multiple oncogenes, cell cycle regulators, tumor suppressors, and DNA repair genes [7]. In this regard, both $\mathrm{Bax}$ and $\mathrm{Bcl}-2$ are vital genes promoting apoptosis, and the sensitivity of cells to apoptotic stimuli is closely related to the ratio of Bcl-2/Bax. Bcl-2 gene, located at 18q21.3, encodes a $25 \mathrm{KDa}$ protein located on the nuclear envelope, cytoplasmic side of the mitochondrial outer membrane, and endoplasmic reticulum [8]. Apoptosis is the programmed cell death that plays an essential role in carcinogenesis. The process of apoptosis involves a number of proteins from the $\mathrm{Bcl}-2$ gene family with different functions. Bcl-2 proteins inhibit the mitochondrial pathway of apoptosis through interaction with other members of the Bcl-2 gene family. Apoptotic disorders are related to the development of malignancies such as gastric cancer [8].

On the other hand, p53 tumor antigen is located at $17 \mathrm{pl} 3$ and is the most frequently altered gene in human cancers. It is a transcription factor expressed at low levels under normal conditions; its expression is increased upon DNA damage, oncogene activation, nutritional deprivation, and hypoxia [9]. P53 is one of the best-studied genes involved in the formation and/or progression of cancer. It plays a crucial role in tumor suppression, and its mutations can be detected in over half of human cancers [10]. Not only anti-tumor transcriptional activity is lost in mutant p53, but also oncogenic functions are often acquired for promotion of tumor proliferation, invasion, and drug resistance [11]. Although many articles have been published concerning p53 abnormality in patients with gastric cancer, its prognostic impact remains controversial [12]. However, the family of Molecules Interacting with CasL (MICAL) destabilizes F-actin in cytoskeletal dynamics by catalyzing actin oxidation/reduction reactions [13]. This family of multidomain proteins has been conserved from insects to humans, and it is increasingly attracting attention due to participation in several key processes in both health and disease [14]. MICAL-1 has been discovered during screening for CasL-interacting proteins, and a search for proteins that bind to the cytoplasmic domain of plexin receptors has led to the discovery of MICALs. Two more MICAL proteins (MICAL-2 and MICAL-3) have been detected in humans and rodents after identifying MICAL-1 [15]. MICAL-2 is likely to be implicated in prostate cancer progression and could be a novel candidate molecular marker or treatment target in this cancer $[13,16]$. Significant overexpression of MICAL2 mRNA has been shown in aggressive, poorly differentiated/undifferentiated, primary human gastric and renal epithelial cancers. Further involvement of MICALs in human cancers has not been explored [13]. Identification of prognostic factors for the diagnosis and determination of optimal therapeutic strategies in patients with gastric cancer is essential [17]. Diagnosis of gastric cancer in the early stages can definitely contribute to better treatment; therefore, the goal of the current study is to investigate the role of $B C L-2$, $B A X, P 53$, and MICAL-2 genes in the early diagnosis of gastric cancer.

\section{Materials and Methods}

This retrospective experimental study was conducted at the laboratory of the Kerman Graduate University of Advanced Technology. Thirty gastric cancer candidates were selected from four hospitals in Kerman (Afzalipour, Fatematalzahra, Payambareazam, Arjmand) in 2017 by random sampling with written permission. The research and its tool were approved by the Research Ethics Committee of Rafsanjan University of Medical Sciences (NO: IR.RUMS.REC.1395.63), and ethical principles were observed during the research. The severity of patients' condition and extensive metastasis were among the reasons for the rejection of samples from which healthy tissue could not be separated from the tumor. Moreover, due to the anesthesia during surgery and lack of standardized nucleic acid stabilization techniques, the tissue could be subjected to hypoxia, changing the expression levels of several genes. Long-term hypoxia 
reduced the local tissue $\mathrm{pH}$, reducing the nucleic acid yield and quantity, as well as deteriorating the sample. Using simple random sampling and random numbers, 30 samples were chosen for this research. The general formula for random sampling is as follows:

$$
\mathrm{P}=1-\mathrm{N}-1 / \mathrm{N} . \mathrm{N}-2 / \mathrm{N}-1 \ldots . \mathrm{N}-\mathrm{n} / \mathrm{N}-(\mathrm{n}-1)
$$

Part of tumor tissue along with adjacent intact tissue (as control) was removed by the surgeon. The samples were kept at $-80^{\circ} \mathrm{C}$ in MEMa to prevent RNA damage. Gastric cancer was diagnosed through appropriate tests, endoscopy, and imaging by specialist physicians. A pathologist was responsible for the diagnosis and separation of tumor tissue from normal tissue. The laboratory mortar was disinfected and autoclaved; then, the tissue samples were cut into small pieces, pulverized in the mortar using liquid nitrogen, and transferred to a $1.5 \mathrm{~mL}$ microtube.

DNA and RNA were extracted using Analytic Jena Kit (Jena, Germany) according to the manufacturer's instructions. Finally, $100 \mu \mathrm{L}$ of elution buffer and $80 \mu \mathrm{L}$ of RNase-free water were added to DNA and RNA filters, respectively, and incubated for one minute at room temperature, followed by centrifugation at $8,000 \mathrm{~g}$ for one minute. The RNAs and DNAs were stored at $-80^{\circ} \mathrm{C}$ and $-20^{\circ} \mathrm{C}$ for the next steps, respectively.

The quantity and quality of DNA and RNA, besides their absorbance, were measured by a spectrophotometer at 260 and $280 \mathrm{~nm}$ wavelengths. The concentration of RNA was calculated using the following formula:

RNA Concentration $(\mu \mathrm{g} / \mathrm{mL})=\mathrm{A} 260 \times 40 \times$ dilution factor

The absorbance ratio was calculated at A260/A280 $\mathrm{nm}$. For a pure RNA and DNA sample, this ratio was 1.8 .

The concentration of DNA was calculated using the following formula:

DNA Concentration $(\mu \mathrm{g} / \mathrm{mL})=\mathrm{A} 260 \times 50 \times$ dilution factor

DNA samples were subsequently stored in a $-20^{\circ} \mathrm{C}$ freezer for later use.

The quality of extracted DNA and RNA was measured using agarose gel electrophoresis [18].

cDNA was synthesized from $1 \mu \mathrm{g}$ of total RNA using Takara Kit according to the manufacturer's protocol. Three specific primer pairs were used in this study, as listed in Table 1. For each primer, the cDNA concentration and cycling time were optimized. The fragments were amplified in a $20 \mu \mathrm{l}$ reaction volume containing $100 \mathrm{ng}$ cDNA. The selected primers were amplified using Takara Master Kit according to the supplier's instruction. The initial concentration of each sample was normalized against the $\beta$-actin reference gene concentration to obtain the expression value.

Table 1. The sequences of primers used for amplifying $B A X, B C L-2, P 53, M I C A L-2$, and $B$-actin genes

\begin{tabular}{|c|c|c|c|}
\hline Primer & Primer sequence & $\operatorname{Tm}\left({ }^{\circ} \mathbf{C}\right)$ & Product Size (bp) \\
\hline \multirow{2}{*}{$\beta$ - actin } & F:GGACATCCGCAAAGACCTGTA & & \multirow[t]{2}{*}{189} \\
\hline & R:ACATCTGCTGGAAGGTGGACA & 57 & \\
\hline \multirow{2}{*}{ MICAL-2 } & F:CAACCCGTGTGTGTCTCATC & 58 & \multirow[t]{2}{*}{209} \\
\hline & R:GTGGATGCCTGGACAAAGTT & & \\
\hline \multirow{2}{*}{ BCL2 } & F: GTGGATGACTGAGTACCTGA & 62 & \multirow[t]{2}{*}{119} \\
\hline & R: AGCCAGGAGAAATCAAACAGA & & \\
\hline \multirow{2}{*}{ Bax } & F: TTTGCTTCAGGGTTTCATCC & 57 & \multirow[b]{2}{*}{154} \\
\hline & R: CAGCTCCATGTTACTGTCCA & & \\
\hline \multirow{2}{*}{ P53-4 } & F:AATGGATGATTTGATGCTGTCCC & & \multirow{2}{*}{273} \\
\hline & R:CGTGCAAGTCACAGACTTGGC & $5 /$ & \\
\hline \multirow{2}{*}{ P53-5 } & F:TTCCTCTTCCTGCAGTACTC & & \multirow{2}{*}{184} \\
\hline & R:TCCGTCATGTGCTGTGACTG & 56 & \\
\hline \multirow{2}{*}{ P53-6 } & F: GCCATCTACAAGCAGTCACA & & \multirow{2}{*}{113} \\
\hline & R: GCCAGACCTAAGAGCAATCA & 57 & \\
\hline \multirow{2}{*}{ P53-7 } & F:TTGTCTCCTAGGTTGGCTCT & 58 & \multirow{2}{*}{110} \\
\hline & R:CAAGTGGCTCCTGACCTGGA & 58 & \\
\hline
\end{tabular}

On the other hand, Primer 3 software was used for designing forward and reverse primers to amplify the region related to $B A X, B C L 2, P 53, M I C A L-2$, and $\beta$-actin (as an internal control) genes. For further confirmation of G-C content, $T_{m}$ temperature, and lack of primer dimers, these primers were assessed by Gene Runner Program (version 3.50 Hasting Software, Inc. 1994). The primers were designed such that to bind only to the desired sequence in the relevant transcript, and they were ordered for synthesis to FAZA Biotech Company.

In this experimental study, real-time-PCR was used to investigate the expression of $\mathrm{Bcl}-2$, Bax, MICAL2, and p53 in normal and tumoral gastric tissues. Moreover, the Bcl-2, Bax, MICAL2, and 
p53 expression ratio were determined. To investigate the genes, Analytik Jena Kit (Jena, Germany) was used as described above. cDNA was synthesized from RNA by enzymes using a primer hybridizing with RNA. The quantity and purity of the extracted RNA were determined using Cary 60 spectrophotometer, and the OD ratio was measured in A260/A280 $\mathrm{nm}$. Samples with OD260/280 equal to 1.8-2.2 were used for cDNA synthesis. The primers specific to the genes were used in this test. PCR reaction was conducted according to the following program. To amplify the gene fragments, after initial denaturation at $95^{\circ} \mathrm{C}$ for 2 minutes, PCR reaction was performed in 33 cycles with the thermal program of $95^{\circ} \mathrm{C}$ for 30 seconds, $58^{\circ} \mathrm{C}$ for 30 seconds, and $72^{\circ} \mathrm{C}$ for 15 seconds. The final elongation step was performed for 5 minutes at $72^{\circ} \mathrm{C}$.

In order to perform PCR-SSCP, PCR products of different samples were analyzed by polyacrylamide gel electrophoresis. First, the PCR products were incubated at $95^{\circ} \mathrm{C}$ for 5 minutes for denaturation and were then immediately transferred to an icechilled container. Polyacrylamide gel (12\%) was used to perform SSCP vertical electrophoresis system. Subsequently, $5 \mu \mathrm{l}$ of PCR product was added to $5 \mu \mathrm{l}$ SSCP buffer (formaldehyde 95\%, sodium hydroxide $10 \mathrm{mM}$, bromophenol blue $0.05 \%$, and xylene cyanol $0.05 \%$ ), and the mixture was loaded into electrophoresis wells.
Electrophoresis was performed for 5 hours at $70 \mathrm{~V}$ in a 0.6 TBE buffer. The gel was stained with silver nitrate. For this purpose, the gel was placed in solution $A$ (ethanol $10 \%$ and acetic acid $0.5 \%$ ) and was then transferred to solution $B$ (silver nitrate $0.1 \%$ ) for 10 minutes. It was eventually placed in solution D (Sodium bicarbonate) and was scanned after washing with distilled water.

In order to verify more precisely, based on the size of the target sequence, $2 \%(\mathrm{w} / \mathrm{v})$ Agarose powder was dissolved in 1X TBE buffer. Later, the gel was kept in ethidium bromide solution for 15 minutes and was then transferred to distilled water for 5 minutes to remove the background stain.

The data were then exported to an Excel worksheet and analyzed with LinRegPCR (v2014.2) program [19].

\section{Results}

Statistical analysis of patients' healthcare records (medical notes) showed that the mean age of the patients was 63 years (75 \pm 11$)$. The most common age group was $60-90$ years, with the predominance of males (66.6\%). In the present study of the prevalence of pathologic findings in gastric cancer, most patients had adenocarcinoma. Tumors were classified as intestinal- (16.6\%), diffuse (10\%) and unknown type $(73.4 \%)$ (Table 2$)$.

Table 2. Demographic overview and statistical analysis of patients

\begin{tabular}{cccc}
\hline & $\begin{array}{c}\text { Frequency of epidemiologic and } \\
\text { malignancy indicators }\end{array}$ & Number & Percentage \\
\hline \multirow{2}{*}{ Age } & $60 \geq$ & 17 & 56.6 \\
\cline { 2 - 4 } Gender & $60<$ & 13 & 43.3 \\
\cline { 2 - 4 } & Male & 20 & 66.6 \\
\hline \multirow{2}{*}{ Tumor type pathology } & Female & 10 & 33.3 \\
\cline { 2 - 4 } & Adenocarcinoma & 27 & 93.3 \\
\hline \multirow{2}{*}{$\begin{array}{c}\text { Pathology of gastric } \\
\text { carcinoma }\end{array}$} & Lymphoma & 0 & 0 \\
\cline { 2 - 4 } & GIST & 3 & 6.6 \\
\hline \multirow{2}{*}{$\begin{array}{c}\text { Tumor differentiation } \\
\text { grade }\end{array}$} & Intestinal & 5 & 16.6 \\
\cline { 2 - 4 } & Diffuse & 3 & 73.3 \\
\cline { 2 - 4 } & Unknown & 22 & 6.6 \\
\hline
\end{tabular}

After extracting DNA and RNA, their purity and quality were read in a Nanodrop device using an RNX-plusTM kit (CinnaGen), and an OD ratio of A260/A280 for RNA was obtained, which is approximately equal to 2 in optimal conditions. Moreover, the extracted DNA and RNA were electrophoresed on agarose gel (Fig. 1). 


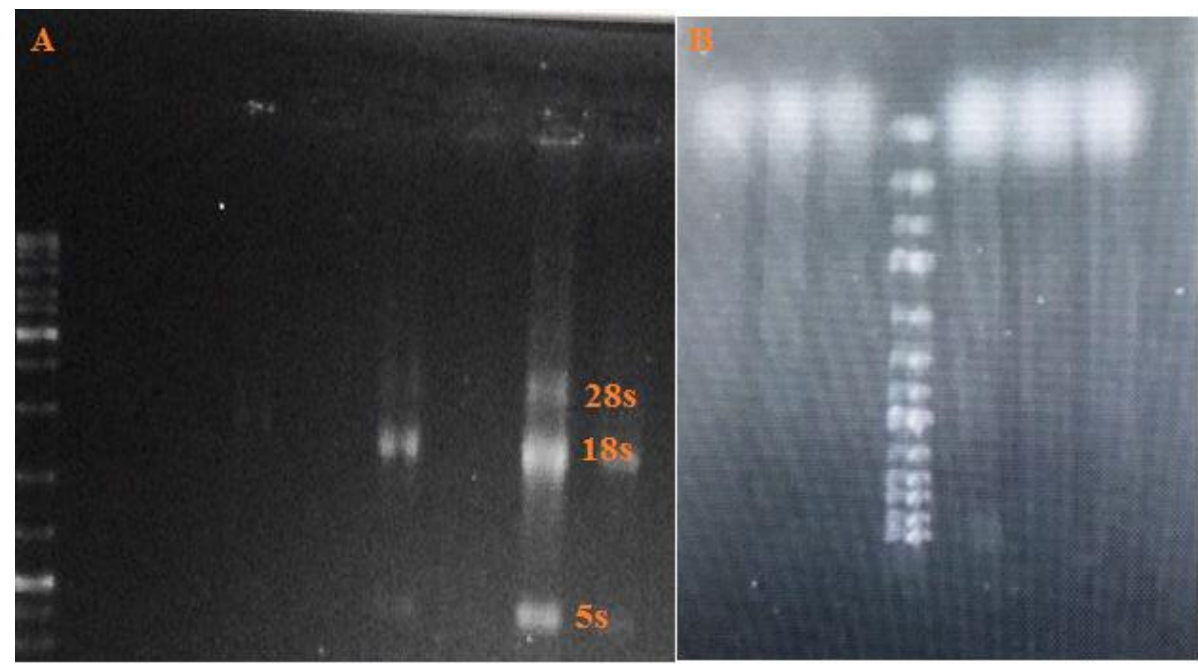

Fig. 1. Agarose gel electrophoresis of total RNA (a) and DNA (b)

PCR products obtained by amplifying exons 4, 5, 6 , and 7 of the p53 gene in $2 \%$ agarose gel from gastric cancer samples are shown in Fig. 2.

For PCR-SSCP (single-strand conformation) of the amplified PCR product, it was placed at $95^{\circ} \mathrm{C}$ for five minutes to be denaturized and was then immediately transferred to an ice pack. Subsequently, according to the method mentioned

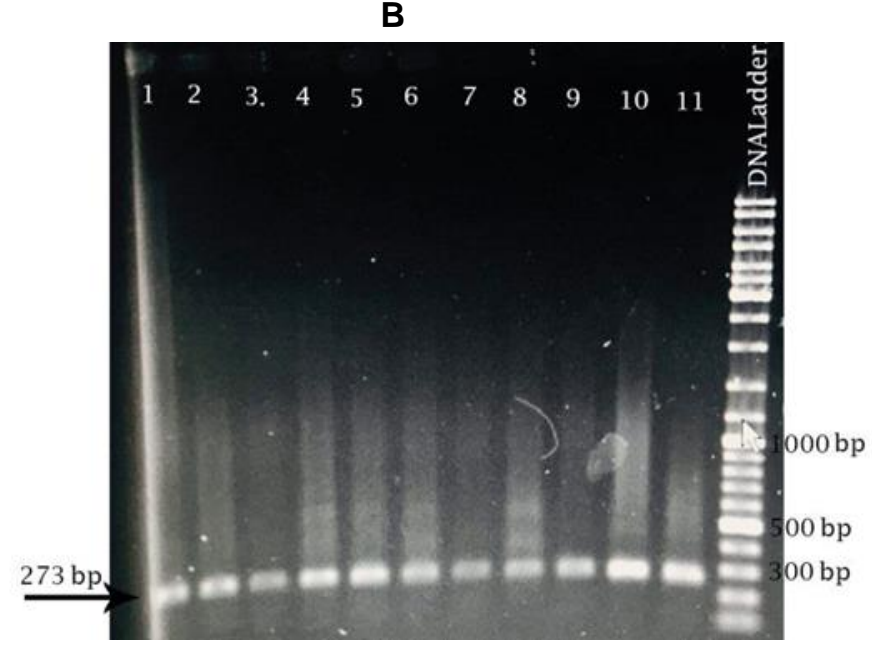

C

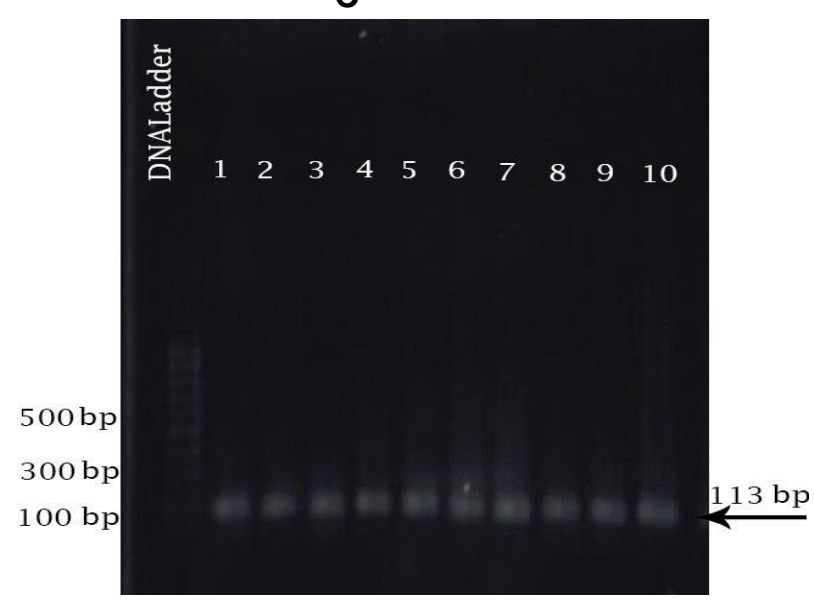

above, the mutations were detected using polyacrylamide gel electrophoresis.

According to PCR-SSCP of the P53 gene, there was $23 \%, 55 \%$, and $7 \%$ mutation in exon 4,6 , and 7, respectively (Fig. 2A). However, based on sequencing results, two cases of deletion (codons 250-253) and one case of missense (codon 248) mutation were detected; the findings are presented in Table 3.

\section{A}

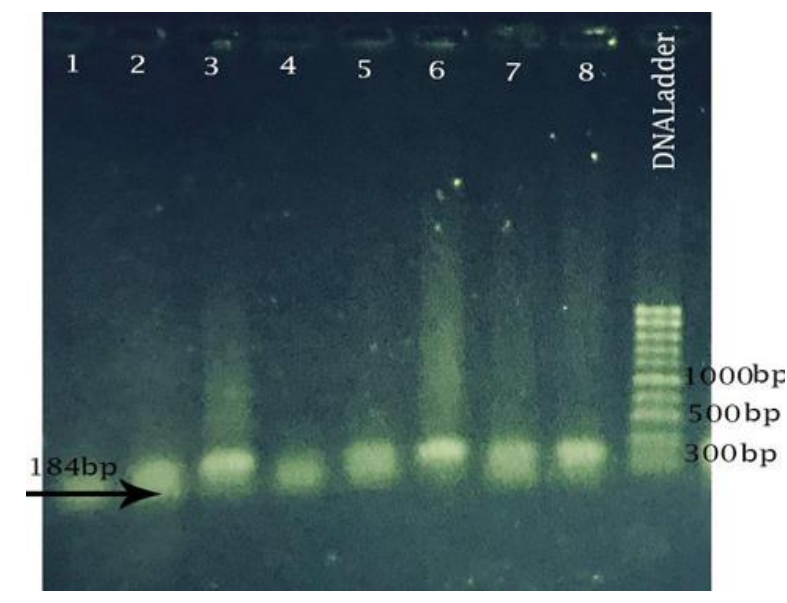

D

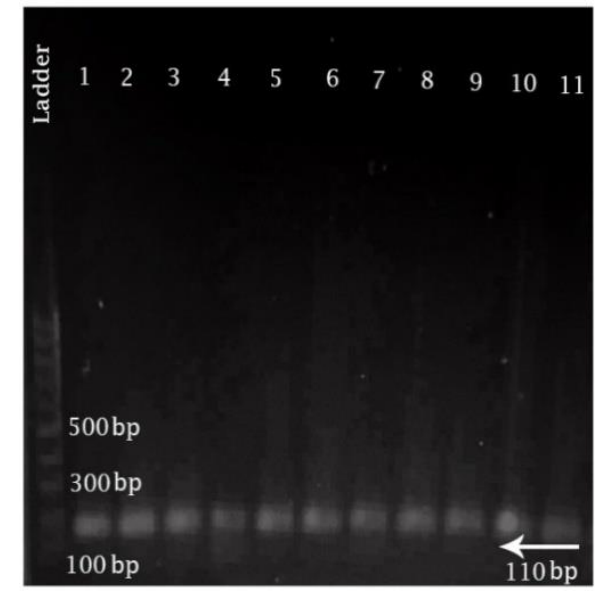

Fig. 2. Electrophoresis of PCR product obtained by amplifying exons $4,5,6$, and 7 in agarose gel $2 \%$ in gastric cancer samples

Fig A: Expression of exon 4 of the p53 gene and the target band (273 bp) in the standard range Fig B: Expression of exon 5 of the p53 gene and the target band (184 bp) in the standard range Fig C: Expression of exon 6 of the p53 gene and the target band (113 bp) in the standard range Fig D: Expression of exon 7 of the p53 gene and the observation band (110 bp) in the standard range 
Table 3. Mutations resulting in changes of $P 53$ in gastric cancer patients

\begin{tabular}{cccc}
\hline Exon number & Type of mutation & Sequence change & Codon number \\
\hline 4 & Deletion & CCATCCTCA & $250-253$ \\
\hline 4 & Missense & CGC- $\rightarrow$ CAG & 248 \\
\hline
\end{tabular}

On the other hand, the quality of the desired band of the P53 and Mical2 gene was observed on polyacrylamide gel (12\%) (Fig. 3).

In the present study, to investigate the molecular

B
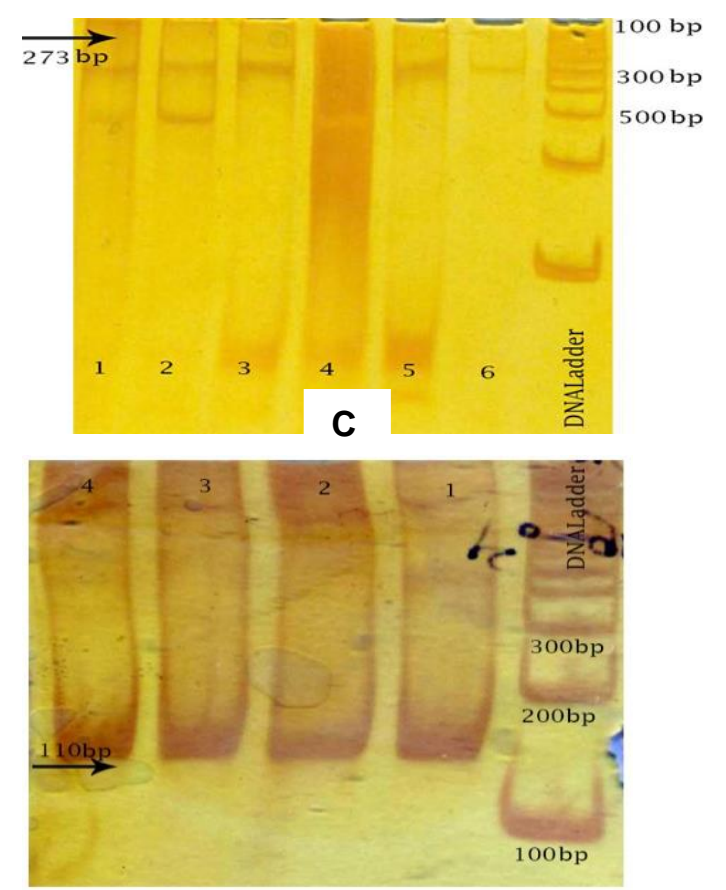

basis for analyzing gastric cancer's pathogenesis, sequencing was used to evaluate the changes in P53 exons between tumors and matched normal samples (Fig. 4).
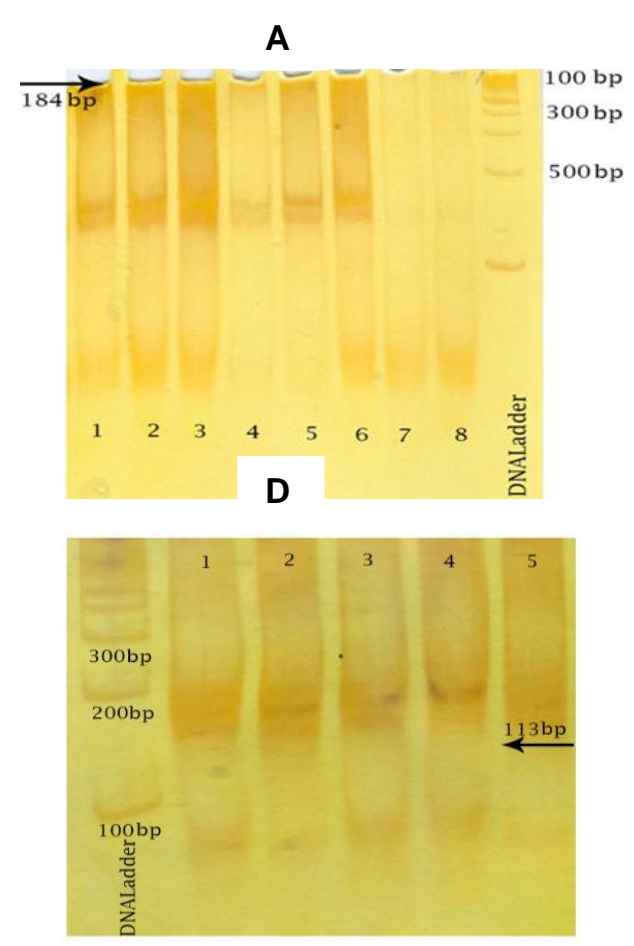

E

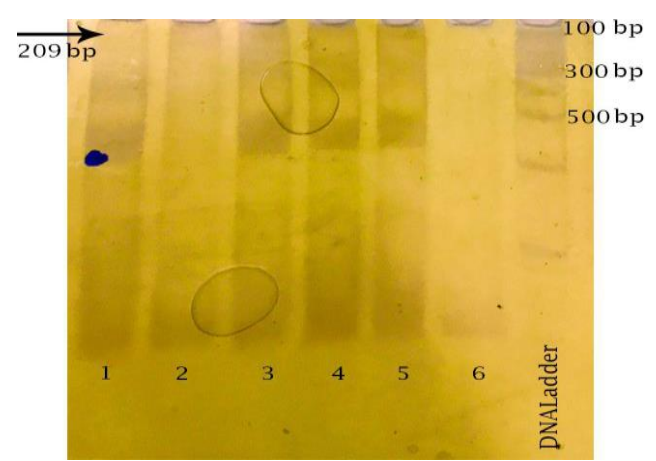

Fig. 3. Silver stained polyacrylamide gel showing the PCR-SSCP pattern of P53 exons and MICAL2 gene to confirm results and possible gene mutations (the case is in both normal and tumor tissues)

Fig A: Targeting Band (273 bp) for Exon 4 of the P53 gene

Fig B: Targeting Band (184 bp) for Exon 5 of the P53 gene

Fig C: Targeting Band (113 bp) for Exon 6 of the P53 gene

Fig $D$ : Targeting Band (110 bp) for Exon 7 of the P53 gene

Fig F: Targeting Band (209 bp) for the MICAL2 gene

In Fig. 3A \& B, wells 1, 3, 5, and 7 were healthy samples, and wells 2, 4, 6, and 8 were tumorous specimens.

In Fig. $3 C \& D$, wells 1,3 , and 5 were healthy samples, and wells 2 and 4 were tumorous specimens.

In Fig. 3E, wells 1, 3, 5 were healthy samples, and wells 2.4,6 were from tumorous specimens. 


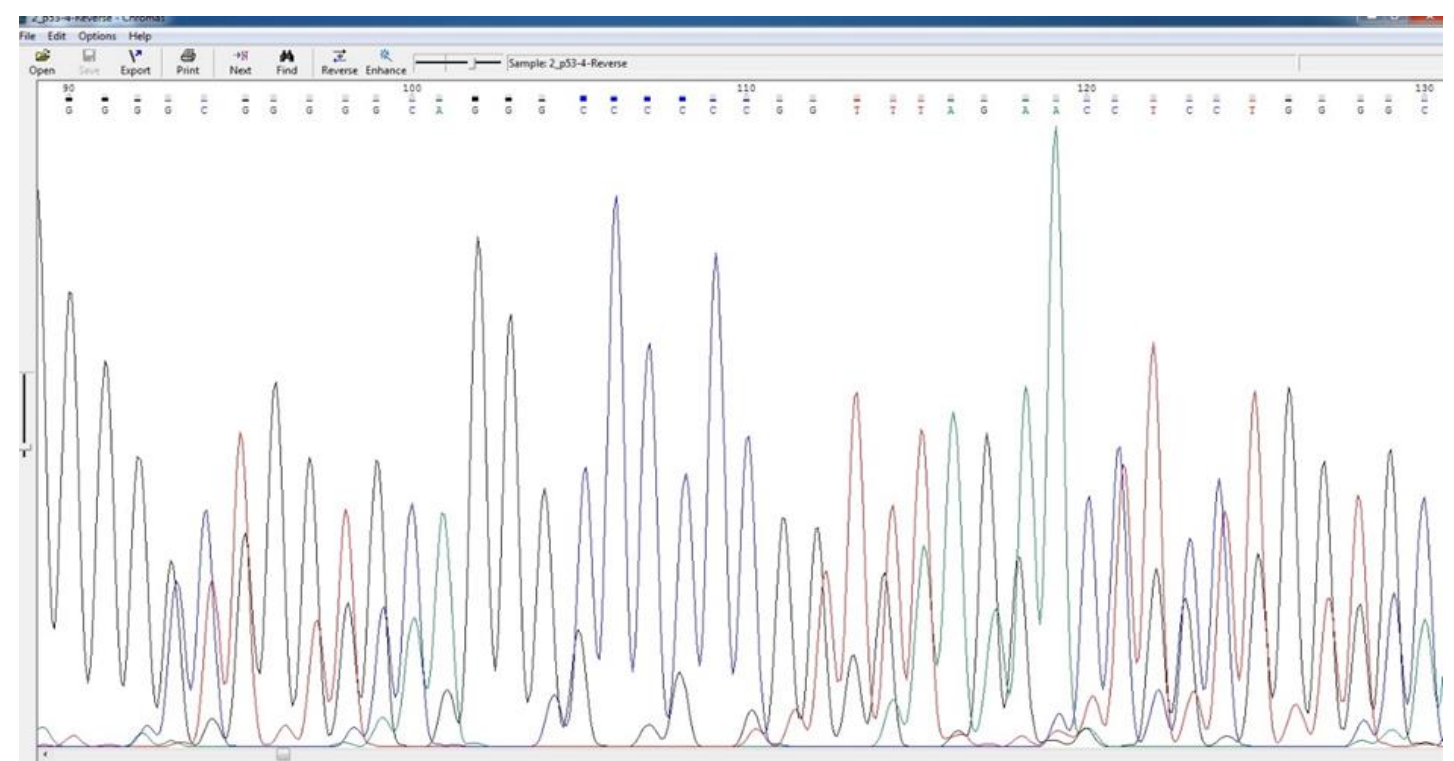

Fig. 4. PCR-SSCP sequencing of Exons 4, 5, 6, and7 of the p53 gene to determine the type of mutation

Amplifying and melting curve analysis of real-time PCR for MICAL2, Bax, BCL2, and $\beta$-Actin genes showed that the amplification had been achieved with appropriate performance (Fig. 5A).
Results of the melting curve for each primer indicated that they acted as specific shapes, with no non-specific patches and secondary structures (Fig. 5B).

A

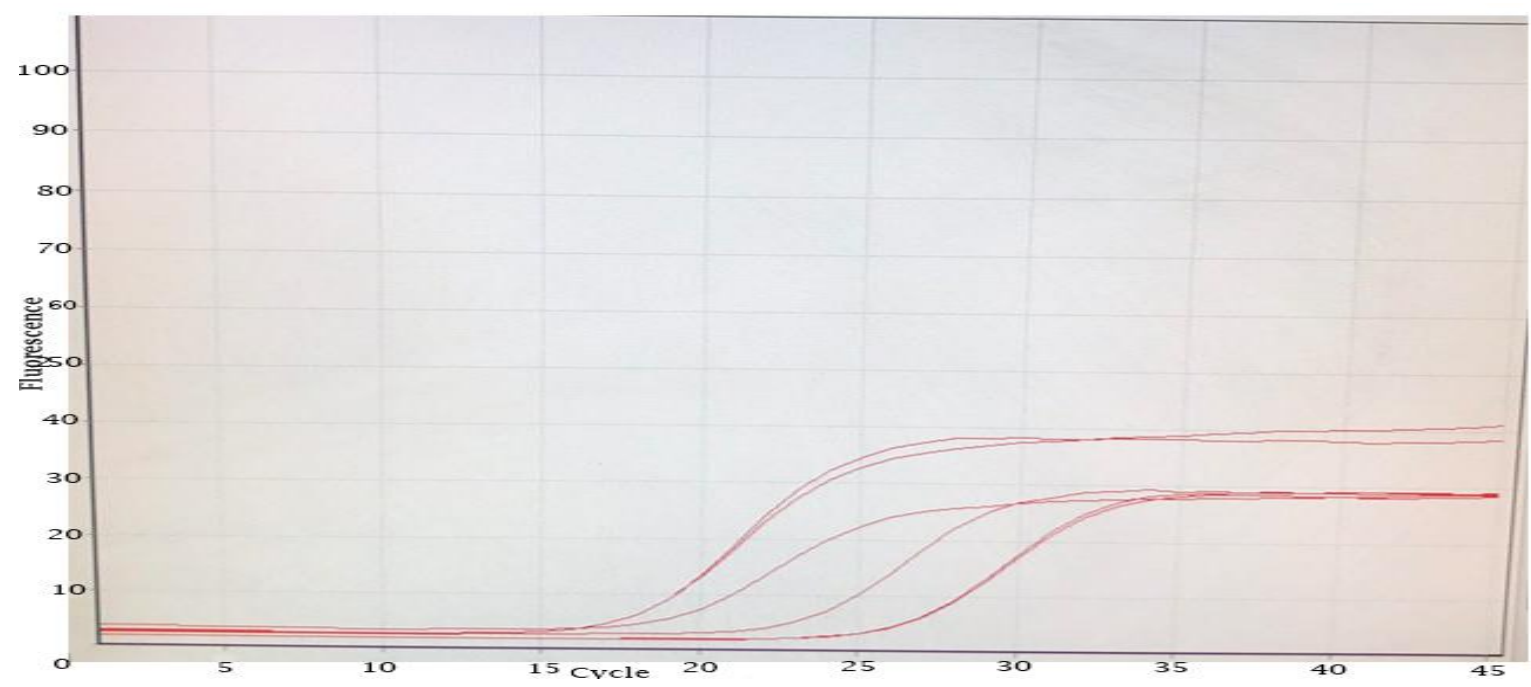

B

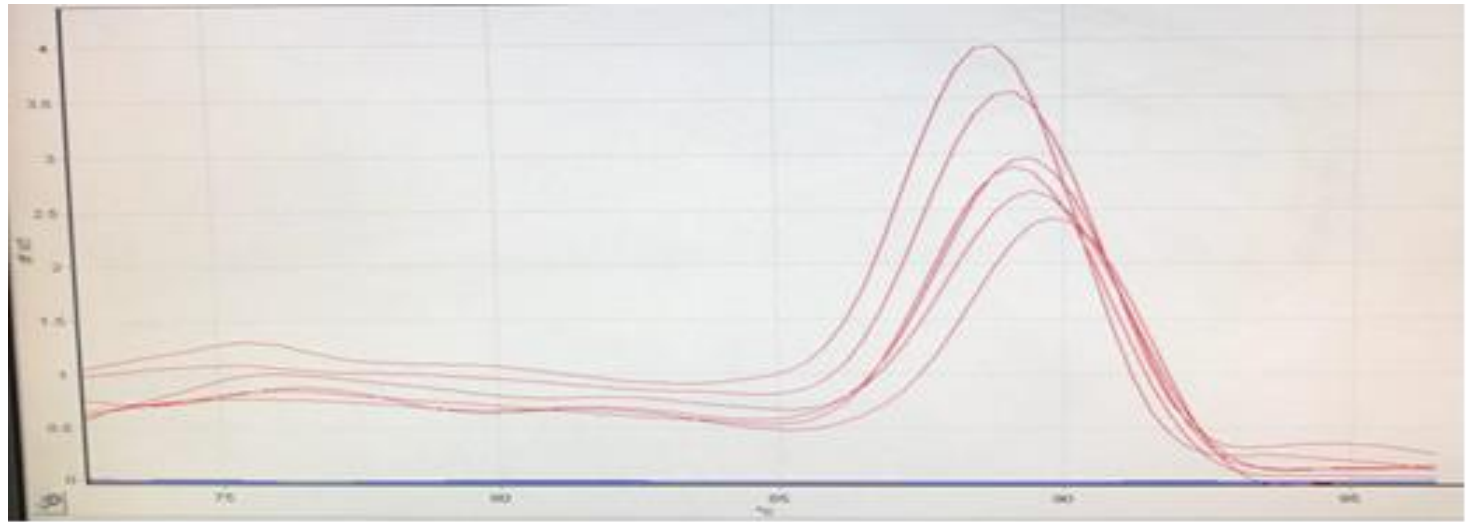

Fig. 5A. Diagram for the amplification of RT-qPCR genes

Fig. 5B. Melting curve of RT-qPCR genomes proving each peak as a PCR product 
According to the results of the RT-qPCR method (evaluating and measuring the expression of BAX, $\mathrm{Bcl}-2$, and MICAL2 genes), the increase in MICAL2 gene expression in tumor tissue was 2.2 fold compared to that of healthy tissue, and $\mathrm{Bcl}-2$ gene expression was 1.54 fold relative to that of healthy tissue. The reduction in Bax gene expression in tumor tissue was 0.87 fold compared to normal tissue (Fig. 6A). Using RT-qPCR, expression results of exons 6 and 7 from the p53 gene on tumor and adjacent normal tissues in gastric cancer patients indicated the increase in p53 gene expression of gastric tumor tissue to be significantly higher than that of healthy. According to this research findings, the expression of exon 6 of the p53 gene in tumor tissue was 2.04 fold compared to the healthy one; also, the expression of exon 7 of this gene and tumor volume was 3.11 fold relative to that of normal (Fig. 6B).

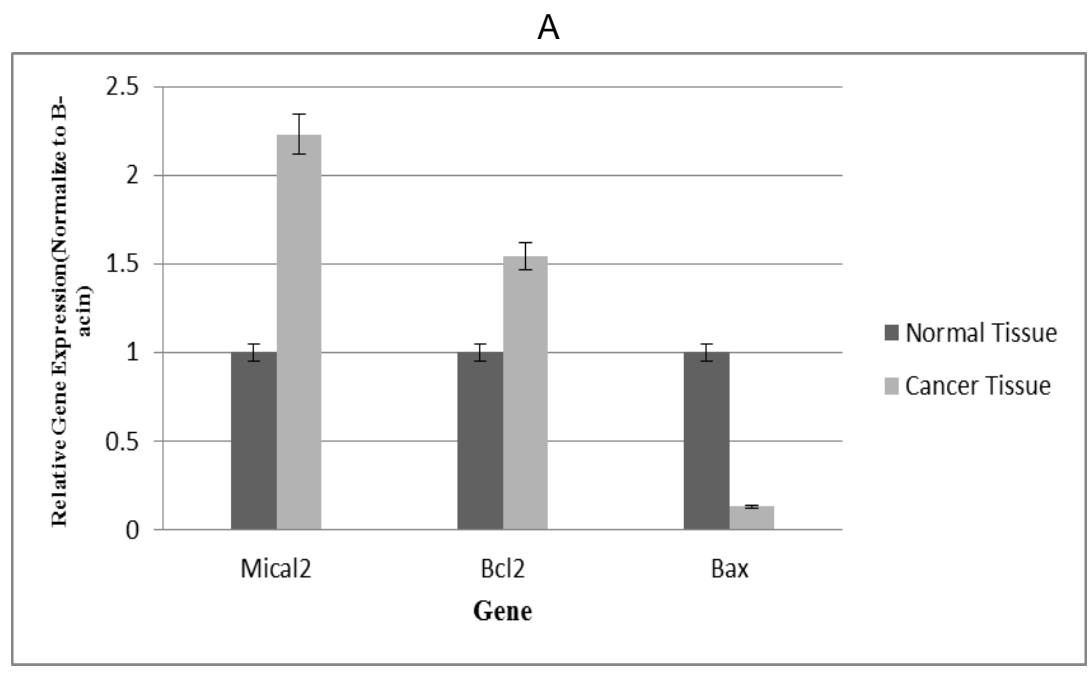

B

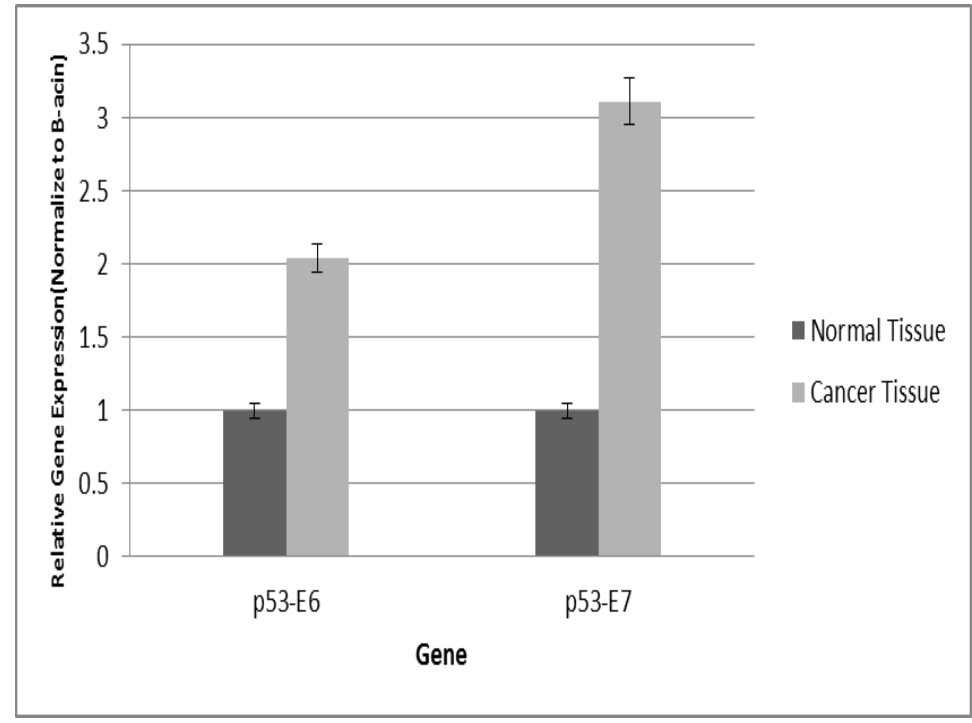

Fig. 6A. Expression diagrams of BAX, BCL2, and MICAL2 genes by RT-qPCR $(p<0.05)$

Fig. 6B. Expression diagrams of exons 6 and 7 of the p53 gene by the RT-qPCR Method

\section{Discussion}

Cancer is a long-term process occurring as a result of abnormal changes in various genes and imbalances in the mechanisms regulating the cell cycle [1]. The pathogenesis of cancer is dependent upon several basic factors, including unchecked cell growth, invasion, angiogenesis, metastasis, and resistance to apoptosis. If one or more of these factors are prevented, cancer cells' growth rate and pathogenicity are decreased [3]. Meanwhile, apoptosis is a physiological process that controls the number of cells in tissues and organs, and each cell has genetic factors capable of directing it towards programmed cell death. Apoptosis also regulates cell differentiation and immune responses. Extracellular factors, including various cellular stresses, regulate different apoptotic pathways [7]. A number of proteins, including P53 and BCL2, are involved in apoptosis induction. The former is implicated in regulating several pro-apoptotic genes, being activated in irreversible damage to DNA to induce the apoptosis process. Inactivation of P53 is an important indicator of several cancers [20, 21]. On 
the other hand, the product of the MICAL2 gene controls epithelial - to - mesenchymal transition (EMT) in human cancer tissue and catalyzes the oxidation and reduction reactions of actin, causing the instability of F-actin in the cytoskeleton. Overexpression of this gene was first observed in epithelial cells of gastric and renal cancers [13], causing EMT in cancer metastasis [14]. Therefore, the extent of the change in the MICAL-2 gene is examined, which can simultaneously cause EMT in gastric tissues. Accordingly, the rate of MICAL-2 gene change can be studied simultaneously with the invasion rate of cancer cells into other tissues, which is referred to as metastasis. Diagnosis of gastric cancer in the early stages is definitely associated with a better response to treatment. In the present study, the mutations of P53 and MICAL2 genes were distinguished using the SSCP-PCR technique. Detection of mutations in P53 and MICAL-2 genes greatly contributes to understanding the genetic mechanism of gastric cancer onset and progression, investigation of mutations causing disease in carriers, and referral to pre-marriage and pre-pregnancy genetic counseling centers, resulting in timely diagnosis and treatment. Moreover, the search for MICAL2 gene mutation can help faster molecular detection of gastric cancer to determine the metastasis stage for its more effective prevention in the carriers. The sensitivity of the SSCP method is dependent upon environmental conditions and the expertise of the researcher, possibly leading to differences in results. There have been few Iranian studies concerning P53 gene mutations in cancer, most of which have been conducted using the PCR-SSCP method, reporting $19-43 \%$ mutation rates; however, DNA sequencing as a sensitive method has not been used for this purpose. A change in codon number 432 has been introduced as a hotspot in gastric and esophageal cancers [22, 23]. In this research, PCR-SSCP was used to determine the changes in P53 and MICAL2 genes. Afterward, to confirm the results and possible mutations of these genes at the DNA level, the SSCP technique was applied, followed by sequencing to confirm the mutation probability. The findings indicated (based on the PCR-SSCP method) a $23 \%$ mutation in exon $4,15 \%$ in exon 5 , $15 \%$ in exon 6 , and $7 \%$ in exon 7 . However, according to sequencing results, there were two cases of deletion (codons 250-253) and one case of missense (codon 248) mutation. In this research, the expression of exons 6 and 7 of the P53 gene was investigated using the RT-PCR method on tumor tissue and its adjacent healthy tissue among gastric cancer patients. The results showed the expression of the p53 gene in gastric cancer patients to be significantly higher than that in healthy people. There have been extensive investigations on the association between the p53 gene and cancer, according to which the gene mutation rates are different depending on the geographical location of the patients. Based on the research findings, the expression of exon 6 of p53 gene was $0.38 \%$ and $2.04 \%$ in healthy subjects and patients with tumor, respectively. The expression of exon 7 of p53 gene in healthy subjects and patients with tumor was $0.47 \%$ and $3.11 \%$, respectively. The results of this study are in line with those of Sanchulli et al., who showed that the expression of p53 gene was increased in esophageal cancer patients [10]. In a study by Meng et al. on breast cancer, $61 \%$ mutation in exon 5-8 of P53 gene was observed [11]. Based on Shiao research in Italy, there was $66 \%$ mutation in P53 genes of gastric cancer patients [12]. However, according to Uchino et al., $25 \%$ and $42 \%$ mutation rates were observed in primary and advanced stages of gastric cancer, respectively [20]. Abbasi et al. examined the expression of P53 and HER-2 gene mutations on tissue samples prepared from patients with gastric cancer using immunohistochemistry (IHC). They showed a direct correlation between gastric cancer histology grade and mutation in P53, as well as between the disease stage and increased HER-2 expression indicating the prognostic value of these two markers in patients with gastric adenocarcinoma [21]. In 2005, Golmohammadi et al. assessed the frequency of mutations in exon 6 of the P53 gene in patients with colorectal cancer in Isfahan province using PCR-SSCP. According to their results, from 40 samples studied, 9 cases (22.5\%) were in the rectal region, and $31(77.5 \%)$ were in different parts of the large intestine. In seven samples (17.5\%), the exon 6 mutation of the P53 gene was observed but was not detected in 33 samples $(82.5 \%)$. This research showed the exon 66 mutation of the P53 gene among the most common exon mutations in colorectal cancers in Isfahan [22]. An investigation was conducted by Maehare et al. in 1999 using immunohistochemistry and monoclonal antibodies on prognostic importance of P53 protein expression in tumor tissues of gastric cancer patients. They concluded that P53 expression was closely related to the advanced gastric cancers and had a poor correlation with prognosis after gastric cancer surgery [23]. In the study of Joushaghani et al., mutations of the P53 gene were examined in 44 biopsy samples from gastric cancer patients in Tehran health centers using PCR-SSCP. After PCR and sequencing the 
desired gene, it was found that the mutation rate of the P53 gene was $20.5 \%$ in gastric cancer, indicating the average frequency of P53 mutation in the studied population [24]. However, Luinetti et al. reported a $26 \%$ mutation rate in the P53 gene even in advanced gastric cancer [25]. As noted above, the rise in tumor grade from I to III increases the rate of positive P53 marker. In a survey by Honda et al., the expression rate of the P53 marker was increased with increasing tumor grade [26]. In similar researches conducted by Yamashita et al. in Japan and the University of Dublin (Ireland) using PCR-SSCP, the mutation rate in exon 6 of the P53 gene was increased in higher tumor grades [27, 28]. In a study by Colomer et al. in Spain (2003), P53 gene expression was negative in 29 out of 100 cases of colorectal cancer using immunohistochemistry; however, the PCR-SSCP method detected mutation in 15 cases, confirming the reliability of the method used in the present study [29]. Subsequently, the expression of BCL-2 and Bax genes was examined on tumor tissue and adjacent unaffected tissue in gastric cancer patients residing in Kerman by Real-Time RT-qPCR. Changes in the expression of these genes are of high importance and lead to the inactivation or dysfunction of proteins encoded by each. RealTime RT-qPCR was used in the current research to study and measure the expression of $B A X$ and $B C L 2$ genes, which showed a $2.2 \%$ increase in the expression of the Bcl-2 gene and a $0.87 \%$ decrease in the rate of Bax gene expression. Koshida et al. revealed a clear relationship between apoptotic pathways and cell division with the expression of BCL2 and Bax genes; however, such association could not be used as a specific biological factor to predict the prevention of invasive cancers [30]. Mro'zek et al. (2003) examined the expression of $B C L 2$ and $B A X$ proteins, as well as mutations in their genes. The outcome of their study showed that mutation in $B A X$ was a prominent feature of the tumor; however, unexpectedly, the mutation in p53 was not observed in unstable tumors. Also, the combined mutation of p53 and Bax genes was considered as a key regulator in the mitochondrial apoptosis pathway but a poor clinical prognostic factor for cancer [31]. Alan C. Taylor et al. stated that the correlation between p53 and oncoproteins for the induction of apoptosis depended on the expression of specific oncoproteins. In addition, the induction of Bax gene is necessary for mediator oncogenes; however, it is insufficient to increase p53-induced apoptosis [32]. Lima et al. (2008), in Brazil, found a close relationship between $\mathrm{H}$. pylori and EBV infections with p53,
Bcl-2, Bax, and C-myc genes expression in gastric cancer. They concluded that gastric cancer could be created in a variety of ways; also, according to their results, $H$. pylori is likely to be involved in the apoptosis process, and EBV inhibits the mentioned genes [33]. In a study conducted in Poland by Gryko et al. on the expression of BID and Bcl-2 genes, it was concluded that $\mathrm{Bcl}-2$ protein has a key role in the gastric cancer process and an increased level of this gene is associated with the progression of gastric cancer [34]. Ho et al., in their study (2012), demonstrated that the expression of MICAL1 and MICAL2 genes in the bladder cell line was significantly higher than that of normal cells [35]. Jalali et al. (2004) investigated the expression of the Bcl-2 gene for the prognosis of breast cancer. Using immunohistochemistry, they found no significant correlation between the expression of this gene and various stages of breast cancer; however, Bcl-2 was considered as an important factor in the prognosis of breast cancer [36]. The expression of the MICAL2 gene was evaluated by Mariotti using RT-PCR and immunohistochemistry, showing a high expression level of this gene in cancer cells at the early stages of tumor invasion [13]. Another study was performed by Zhou et al. on gastric cancer cells to investigate the association between $\mathrm{Bcl}-2$ and Ki67 genes with age and gender, as well as metastasis stage of tumor cells. However, no significant difference was found between the expression of these genes with age and gender nor metastasis stage of tumor cells [17]. Ataei et al. in Mazandaran studied the expression of the BCL2 gene in patients with gastric cancer. In this research, the samples were collected from healthy and tumor tissues, and the desired gene was amplified and assessed using the PCR method after DNA extraction. Although this gene is a key factor in regulating apoptosis and developing cancer cells, the results showed that the expression of the BCL2 gene in tumor cells was significantly lower than in control samples, possibly due to the low number of cases [8].

In the present study, the mean age of patients was 63 years. The most commonly affected age group was 59-69 years, and most patients were men. According to the pathologic findings of gastric cancer, the majority of patients had adenocarcinoma. Out of 50 patients with adenocarcinoma, $16.6 \%$ had the intestinal type, $10 \%$ the diffused type, and $73.3 \%$ the unknown type. Based on global studies, adenocarcinoma is the most common form of gastric cancer [6]. It should be noted that the intestinal type of gastric adenocarcinoma is the most frequent form of this cancer, which is a function of chronic inflammation 
due to $\mathrm{H}$. pylori infection associated with chronic gastritis that causes atrophic gastritis, intestinal metaplasia, glandular dysplasia, and adenocarcinoma. Collectively, a gastric cancer diagnosis in the early stages is definitely associated with a better response to treatment. This study aims to determine the changes in the expression of $B A X$ and $B C L-2$ and distinguish the mutation in P53 and MICAL2 genes in patients with gastric cancer in Kerman. As the changes of P53, MICAL-2, BAX, and BCL2 genes can cause the inactivation or dysfunction of the proteins encoded by each, the value of molecular analysis of these genes in patients is evaluated in patients with gastric cancer. Determining mutations of these genes contributes considerably to understanding the genetic mechanism of the onset and progression of gastric cancer, investigation of the disease-causing genes in carriers, and referral of patients to pre-marriage and pre-pregnancy genetic counseling centers for timely diagnosis and treatment of such cancer. Moreover, determining the mutations in P53 and MICAL2 genes can be effective for faster molecular diagnosis and metastasis stage detection for more efficient prevention of gastric cancer in carriers. In conclusion, the findings of the present study demonstrate that molecular monitoring of P53, MICAL-2, BCL2, and BAX genes allows early identification of patients with a remarkably higher risk of gastric cancer, possibly helping to define the probability of response to conventional chemotherapy regimens.

\section{Conclusion}

The data suggest that the changes in the $B A X$, $B C L 2$, P53, and MICAL-2 genes play a key role in gastric cancer.

\section{Acknowledgement}

This project was financially supported by a grant from the Rafsanjan University of Medical Science. We appreciate the cooperation of all the medical staff from Kerman hospitals, who kindly helped us collect samples and diagnose gastric cancer patients. This article is extracted from the thesis of Rafsanjan University of Medical Sciences, MSc of Clinical Biochemistry.

Conflict of interest: None declared.

\section{References}

1. Weinberg R. The biology of cancer. $2^{\text {nd }}$ ed. New York, United States: w. w. norton \& company;; 2013.
2. Xu Gf, Zhang WJ, Sun Q, Xu X, Zou X, Guan $W$. Combined epithelial-mesenchymal transition with cancer stem cell-like marker as predictors of recurrence after radical resection for gastric cancer. World J Surg Oncol 2014; 12:368.

3. Kanda M, Kodera Y. Recent advances in the molecular diagnostics of gastric cancer. World $\mathrm{J}$ Gastroenterol 2015; 21(34):9838.

4. Malekzadeh R, Derakhshan MH, Malekzadeh Z. Gastric cancer in Iran: epidemiology and risk factors. Arch Iran Med 2009; 12(6):576-83.

5. Lajus TB, Sales RM. CDH1 germ-line missense mutation identified by multigene sequencing in a family with no history of diffuse gastric cancer. Gene 2015; 568(2):215-9.

6. De Vries AC, Kuipers EJ. Review article: Helicobacter pylori eradication for the prevention of gastric cancer. Aliment Pharmacol Ther 2007; 26 Suppl 2:25-35.

7. $\mathrm{Yu} Q$. Restoring p53-mediated apoptosis in cancer cells: new opportunities for cancer therapy. Drug Resist Updat 2006; 9(1-2):19-25.

8. Mirmajidi SH, Ataee R, Barzegar A, Nikbakhsh $\mathrm{N}$, Shaterpour M. Low Expression of the bcl2 Gene in Gastric Adenocarcinomas in Mazandaran Province of Iran. Asian Pac J Cancer Prev 2015; 16(14):6067-71.

9. Zhao D, Tahaney WM, Mazumdar A, Savage MI, Brown PH. Molecularly targeted therapies for p53-mutant cancers. Cell Mol Life Sci 2017; 74(22):4171-87.

10. Motalleb G, Sancholi S, Yegane Moghadam A, Talaee R. P53 gene expression evaluation in patients with esophageal cancer using reverse transcriptase real time polymerase chain reaction. Pajoohandeh 2015; 20(3):154-62.

11. Meng L, Lin L, Zhang H, Nassiri M, Morales AR, Nadji M. Multiple mutations of the p53 gene in human mammary carcinoma. Mutat Res 1999; 435(3):263-9.

12. Shiao $Y H$, Rugge $M$, Correa $P$, Lehmann HP, Scheer WD. P53 alteration in gastric precancerous lesions. Am J Pathol 1994; 144(3):511-7.

13. Mariotti S, Barravecchia I, Vindigni C, Pucci A, Balsamo M, Libro R, et al. MICAL2 is a novel human cancer gene controlling mesenchymal to epithelial transition involved in cancer growth and invasion. Oncotarget 2016; 7(2):1808-25.

14. Vanoni MA. Structure-function studies of MICAL, the unusual multidomain flavoenzyme involved in actin cytoskeleton dynamics. Arch Biochem Biophys 2017; 632:118-41.

15. Zhou Y, Gunput RA, Adolfs Y, Pasterkamp RJ. MICALs in control of the cytoskeleton, exocytosis, and cell death. Cell Mol Life Sci 2011; 68(24):4033-44.

16. Ashida S, Furihata M, Katagiri T, Tamura K, Anazawa $\mathrm{Y}$, Yoshioka $\mathrm{H}$, et al. Expression of novel molecules, MICAL2-PV (MICAL2 prostate cancer variants), increases with high Gleason score and prostate cancer progression. Clin Cancer Res 2006; 12(9):2767-73. 
17. Zhou $\mathrm{Y}$, Li $\mathrm{Y}$, Zheng J, Liu K, Zhang $\mathrm{H}$. Detecting of gastric cancer by $\mathrm{Bcl}-2$ and Ki67. Int J Clin Exp Pathol 2015; 8(6):7287.

18. Karimabad MN, Mahmoodi M, Jafarzadeh A, Darehkordi A, Hajizadeh MR, Khorramdelazad $\mathrm{H}$, et al. The novel Indole-3-formaldehyde (2AITFEI-3-F) is involved in processes of apoptosis induction? Life Sci 2017; 181:31-44.

19. Ruijter JM, Ramakers C, Hoogaars WM, Karlen Y, Bakker O, van den Hoff MJ, et al. Amplification efficiency: linking baseline and bias in the analysis of quantitative PCR data. Nucleic Acids Res 2009; 37(6):e45.

20. Uchino S, Noguchi M, Ochiai A, Saito $T$, Kobayashi M, Hirohashi S. p53 mutation in gastric cancer: a genetic model for carcinogenesis is common to gastric and colorectal cancer. Int J Cancer 1993; 54(5):75964.

21. Abbasi M, Mobaien A, Majlesi A, Kamalian N, Monsef A. A Survey of p53 and HER-2/neu Over Expression in Patients with Gastric Cancer and Correlation with Prognosis. Avicenna Journal of Clinical Medicine 2008; 15(3):5-10.

22. Golmohamadi $R$, Nikbakht $M$, Salehi $M$, Mokhtari M. Detection of P53 exon 6 mutions in colorectal cancer patients by PCR-SSCP method in Isfahan Hospital during 2004-2005. Feyz 2006; 10(2):1-6.

23. Maehara $Y$, Tomoda M, Hasuda S, Kabashima A, Tokunaga E, Kakeji Y, et al. Prognostic value of p53 protein expression for patients with gastric cancer- - a multivariate analysis. $\mathrm{Br} \mathrm{J}$ Cancer 1999; 79(7-8):1255-61.

24. Joshaghani HR, Koochaki E, Amini R, Derakhshandeh P, Ehsani A, Shabani M, et al. Determination of $\mathrm{P} 53$ gene mutations in gastric cancer by PCR-SSCP. Journal of Gorgan University of Medical Sciences 2003; 5(2):3642.

25. Luinetti O, Fiocca R, Villani L, Alberizzi $P$, Ranzani GN, Solcia E. Genetic pattern, histological structure, and cellular phenotype in early and advanced gastric cancers: evidence for structure-related genetic subsets and for loss of glandular structure during progression of some tumors. Hum Pathol 1998; 29(7):702-9.

26. Honda T, Tamura G, Endoh Y, Nishizuka S, Kawata S, Motoyama T. Expression of tumor suppressor and tumor-related proteins in differentiated carcinoma, undifferentiated carcinoma with tubular component and pure undifferentiated carcinoma of the stomach. Jap
J Clin Oncol 2005; 35(10):580-6.

27. Yamashita K, Yoshida T, Shinoda H, Okayasu I. Novel method for simultaneous analysis of p53 and K-ras mutations and p53 protein expression in single histologic sections. Arch Pathol Lab Med 2001; 125(3):347-52.

28. Leahy DT, Salman R, Mulcahy H, Sheahan K, O'Donoghue DP, Parfrey NA. Prognostic significance of p53 abnormalities in colorectal carcinoma detected by PCR-SSCP and immunohistochemical analysis. J Pathol 1996; 180(4):364-70.

29. Colomer A, Erill N, Verdú M, Roman R, Vidal A, Cordon-Cardo $\mathrm{C}$, et al. Lack of p53 nuclear immunostaining is not indicative of absence of TP53 gene mutations in colorectal adenocarcinomas. Appl Immunohistochem Mol Morphol 2003; 11(2):130-7.

30. Koshida Y, Saegusa M, Okayasu I. Apoptosis, cell proliferation and expression of $\mathrm{Bcl}-2$ and Bax in gastric carcinomas: immunohistochemical and clinicopathological study. Br J Cancer 1997; 75(3):367-73.

31. Mrozek A, Petrowsky H, Sturm I, Kraus J, Hermann S, Hauptmann S, et al. Combined p53/Bax mutation results in extremely poor prognosis in gastric carcinoma with low microsatellite instability. Cell Death Differ 2003; 10(4):461-7.

32. Taylor AC, Schuster K, McKenzie PP, Harris LC. Differential cooperation of oncogenes with p53 and Bax to induce apoptosis in rhabdomyosarcoma. Mol Cancer 2006; 5:53.

33. Lima VP, de Lima MA, André AR, Ferreira MV, Barros MA, Rabenhorst SH. H pylori (CagA) and Epstein-Barr virus infection in gastric carcinomas: correlation with p53 mutation and c-Myc, Bcl-2 and Bax expression. World J Gastroenterol 2008; 14(6):884-91.

34. Gryko M, Pryczynicz A, Zareba K, Kędra B, Kemona A, Guzińska-Ustymowicz K. The expression of $\mathrm{Bcl}-2$ and $\mathrm{BID}$ in gastric cancer cells. J Immunol Res 2014; 2014:953203.

35. Ho JR, Chapeaublanc E, Kirkwood L, Nicolle R, Benhamou S, Lebret $\mathrm{T}$, et al. Deregulation of Rab and Rab effector genes in bladder cancer. PloS One 2012; 7(6):e39469.

36. Jalali Nadoushan MR, Davati A, Tavakoli A. Expression of $\mathrm{Bcl}-2$ Gene in Primary Breast Cancer and its Correlation with Some Prognostic Factors. Journal of Mazandaran University of Medical Sciences 2007; 17(58):306. 